\title{
COMPETITIVE INTELLIGENCE: IMPORTANCE AND APPLICATION IN PRACTICE
}

\section{Šaban Gračanin (1), Edin Kalac (2), Dejan Jovanović (3)}

${ }^{(1)}$ Ph.D. candidate, University of Kragujevac, Faculty of Economics,

(2) Ph.D. Independent consultant,

(3) Ph.D. candidate University of Kragujevac, Faculty of Economics

Šaban Gračanin, Ph.D.

University of Kragujevac, Faculty of Economics Đure Pucara Starog 3 , 34,0o Kragujevac, Srbija saban.gracanin@hotmail.com

Article info

Paper category: Preliminary paper Received: 23.6.2015. Accepted: 23.09.2015. JEL classification: D83, $\mathrm{L}_{6} \mathrm{O}, \mathrm{O}_{12}, \mathrm{O}_{52}$ 


\begin{abstract}
Paper represents positive effects of competitive intelligence (CI) usage in the process of strategic decision making within the company. We analyze current state of CI awareness in Serbian businesses, and influence of CI on business performance of companies operating in Serbia. Study provides empirical comparative data on competitive intelligence implementation practices in developed countries and Serbia. Survey results, based on summarising and comparative analysis offield data, indicate that there are small differences in practical implementation of CI between companies in Serbia and those in EU. We indentified differences between the CI practices in Japan and USA on one side, and EU countries and Serbia on the other. Research aim is to make an assessment of competitive intelligence systems application in practice, and to provide necessary recommendations for companies based on the "best CI practices" in most developed countries, as well as basis for future studies.
\end{abstract}

\title{
Keywords:
}

Competitive intelligence, Competition information, Strategic decision-making, Competitive advantage, Serbian large companies 


\section{INTRODUCTION}

In modern business environment, knowledge is the most important resource. Valid market positioning and development of corporative strategies are unthinkable without consideration of competition, both current and potential, related information.

By the end of the last century, information regarding competition mainly concerned their market share and offer, which at that time showed to be a satisfactory volume of information. However, the exceptional complexity and volatility of the modern business environment nowadays, requires much broader information about the competition, current and potential. These informations refer not only to competitors market share and their offer, but also to the level and structure of their expenses, products and services quality-price relations, sales volume, scope of activities, cash flows, liquidity, solvency and profitability.

Information about competition are nowadays critical component for both, tactical and strategic decision making of every company. Building information system that supports the management and decision-making, and that can be a source of competitive advantage, is not an easy task. Turbulent development of information technologies, hardware and software, tranformed activites such as collection, accumulation and broadcasting of information, into a very easy task, but only from the technical side. What remains problem is how to get quality and useful information. Such high-quality information about competition companies may have on its disposal only if they establish integrated and intelligent system for collecting and analyzing data about the competition. This system is known as "intelligent system for the notification of competition" (Competitive Intelligence-CI). CI provides critical informational support to both tactical and strategic decision-making, and is becaming irreplacable tool in the modern competitive struggle.

There is no single and universal definition of CI. The most commonly used and cited definition of CI was provided by the Society of Competitive Intelligence Professionals-SCIP ${ }^{1}$ where $\mathrm{CI}$ is defined as: "the process of monitoring the competitive environment. CI enables managers in companies of all sizes to take decisions about everything - marketing, research and development, investments and long-term business strategies. CI is a continuous process, which includes legal and ethical collection of information, analysis that does not avoid unwanted conclusions, and controlled dissemination of knowledge and information to decision-makers.

CI process includes collecting, analyzing and providing timely and useful information and knowledge, which are essential for managers and all decision makers for improving competitive position of their companies - in the eyes of consumers. (Cobb, 2003: 81). Competitive intelligence provides tools for transforming raw in-

1 SCPI is a global non-profit organization that deals with issues of development and practical use of competitive intelligence. Today SCPI is an abbreviation for Strategic and Competitive Intelligence Professionals, previously known as the Society of Competitive Intelligence Professionals. More at http://www.scip.org 
formation regarding the competitive environment in the information and knowledge that is used to make strategic business decisions.

Companies that understand this concept, generate a lot more success in the market than their competitors who do not understand the relationship between environmental scanning and strategic decision-making.

\section{COMPETITIVE INTELLIGENCE IMPACT ON THE PROCESS OF STRATEGIC MANAGEMENT}

Basic task of modern strategic management is designing and implementation of winning strategies. Generally speaking, the "winning" strategy enables sucesfull market postitioning of companies. Superior market positioning, means delivering the highest value to customers, at the lowest cost. Achieving such leading market position has become increasingly difficult task in the modern global marketplace, due to the increasing pace and intensity of competition. Companies that fail to timely seize new market opportunities and to defend themselves from the threat of competitors, very soon realize that their competitive market position weakened. By losing a leading market position, companies lose their competitive advantage, and by time suffer deteriorating financial results.

Numerous studies and researches in the past, showed that process of strategic decision-making must not ignore the strategic actions of current and potential competitors, and that companies must make an extra effort to ensure these information, regardles in which branch they operate.

Competitors related information research and analyzing, has its roots in the scientific literature that stretches back to Aguilar, who claimed that the environment creates significant limitations and minimizes the possibility of managers to use and analyze information coming from the market. Companies that are able to adapt and adjust their business strategies, based on continuous inflow of information about their competitors, will enhance their competitive advantage over those companies that do not try or fail to adjust (Aguilar, 1967).

Porter argues that analysis of the competition is the central problem in the process of strategy defining. Without these information, companies will find it very difficult to position themselves within the market, in a way that sets them apart from competitors. Understanding current market positions and strategies of competitors, is the basis for designing future strategies. Without this information, it is almost impossible to assess the opportunities and competencies of its main competitors in the market (Porter, 1980).

Hovewer, until recently, only few researchers focused their research on identifying the relationship between strategic management process and activities that management undertake in order to understand their competitive environment. Competitive intelligence is the connection between these these two procesess. Lat- 
est surveys confirmed that companies can apply CI in order to: understand how and where to find unique resources and capabilities which can improve their position on the market and struggle with competition; to estimate unique way of combining its resources for creating values for its customers; to appraise abilities of rivals to imitate their strategies; to comprehend the way their rival developed its unique capabilities; to create "knowledge storages" throughout organization by introducing skills managements systems and activities within the company; to prevent erosion of information and skills regarding the grounds on which company bases its competition advantages by applying counter-intelligence strategies which are used for the protection of key processes in operative activities of a company. (Kersi, Antia, Hesford, 2007; Stephanie, 2005; Marin, Poulter, 2004).

Development, integration and application of competitive intelligence serve in purpose to increase value for the customers. (Blenkhorn, Fleisher, 2001). Development of CI is an important process for every organization for several reasons: by gathering information about competition companies are able to analyze their skills and competences, enhance their own, as well as to predict future behavior and actions of competitors in order to preserve or improve its market position. More importantly, CI creates comparative knowledge that enables companies to highlight their strengths and improve the weaknesses of their competitors through product differentiation and/or services offered on the market (Cobb, 2003: 81). Companies which are increasingly implementing environmental scans, and invest in CI information systems for the processing and distribution of data, lunch their products on the market more successfully than their competitors (Kumar, Subramanian, Strandholm, 2001: 31).

Maybe the most important fact that needs to be emphasized, is that CI itself can be a source of sustainable competitive advantage, enabeling company to develop and implement strategies that improve business efficiency and effectiveness. (Daft, 1983: 136). The key of designing a successful strategy is the ability to identify, develop and maintain a competitive advantage over rivals. Resource or capability can be a source of sustainable competitive advantage, if it can produce profits for the company, in a manner which competitors on the market have difficulty to replicate or mimic.

CI activities arguably represent a source of sustainable competitive advantage, for all companies that successfully use it in three ways : first by making useful, timely and relevant information CI positively influence the process of forming strategy, providing key information on business environment and competitors during the critical phase of the strategic decision-making; secondly, specific and accumulated knowledge of CI employees can positively influence the process of implementation and development strategies, by ensuring that the accumulated knowledge and information are communicated to decision makers, and that information and knowledge are integrated into all discussions of management related to the process of strategic management, third - continuous use and development of CI activities within a single 
company, creates increasing market barriers to competition, and can be a source of sustainable competitive advantage for those companies which are dedicated to developing and maintaining their CI activities.

\section{APPLICATION OF COMPETITIVE INTELLIGENCE IN PRACTICE - LITERATURE REVIEW}

As the need for an improved supply of information has become widely accepted in the last decade, many companies are considering on daily bases the possibility of developing and implementing CI activities. Companies worldwide are becoming more aware about the value and usefulness of investments in new, modern management concepts, such as investment in CI programs.

Hovewer, to fully understand the CI process, its contribution to the development of companies competitive strategies and sustainable competitive advantages, as well as exploring potencials for further development and implementation of these systems, it is very important to further analyse experiences regarding practical application of CI sistems, in order to be abble to more precisely define answers regarding :

- organization types and implementation methods of CI activities in practice,

- key users of CI informations,

- importance of CI for strategic business decision-making,

- contribution of CI systems for the improvement of business results of the company

- options to improve CI systems practical implementation and potencials exploring.

Surveys of practical use of CI throughout the world, show that basic CI activities (CI cycle) have been performing all over the world. Most of large companies in developed countries are using some types of CI techniques, while small companies are using CI techniques only on occasional basis. Companies based in countries in transition perform similar CI procesees as those practiced in developed countries, but with the use of less sophisticated software and techniques. Publicly available and easy accessible information are the primary source of data for CI analysis for all companies. In developed countries, CI professionals are obsessed with information and web tools for gathering information. On the other hand, companies in developing countries are using its employee's networks and intelligence as the main sources of information for the CI analysis.

There are different types of CI techniques (early warning, formulation of strategies, implementation of strategies), which are performed in different areas (sales, planning, research and development, production, corporate level etc.) within corporate companies. However, very little is known about the evolution of CI activities and programs. General conclusion is that managers and other users of CI worldwide still do not use knowledge and information offered by CI systems, at least not as much as 
they should in order to be able to use this information to develop sustainable competition advantages on the market. (Ganesh, Miree, 2003: 2).

Erickson and Rothberg explored level of competitive intelligence activity in firms in business oriented vs. consumer-oriented industries. Main conclusion of their research is that the level of competitive intelligence is higher in consumer industries than business-to-business (Erickson, Rothberg, 2009: 163).

Regarding the literature on CI and hereby especially country-specific studies, CI as a company practice appears to be very popular in the United States, with most of the literature related to this topic stemming from US-based researchers and/or practitioners. Outside the USA only a few empirical studies have been published by European researchers. In text below we present country-specific empirical studies on CI from different parts of the EU and other developed world countries, in order to give an overview on previous studies objectives and conclusions.

In 1995, comprehensive study was carried out in North America, whose aim was to present CI practices in US, and to systematically describe and analyse them (Prescott and Bhardwaj, 1995). The survey instruments of this study were replicated trice, exploring the CI awareness and application in China (Tao and Prescott, 2000), Japan (Sugasawa, 2004) and Austria (Roitner, 2004).

Similar studies were conducted by Hannula and Pirttimaki (Hannula, Pirttimaki, 2003), who carried out survey targeting the top 50 Finnish companies in order to find out how popular CI practices are, and in which way CI is currently applied in Finland. Another research (De Pelsmacker, et all, 2005) investigated Belgian and South African exporters, and indicated that companies which were using CI improved its abilities to anticipate threats and opportunities in the marketplace.

In several EU countries, such as France (Smith and Kossou, 2008), Spain (Tena and Comai, 2004), Germany (Michaeli, 2004), Sweden (Hedin, 2004), Lithuania (Stankeviciute et al., 2004) and the UK (Wright et al., 2004) empirical studies on CI in general have also been carried out. General conclusion of these studies is that CI systems provide sophisticated information and intelligence, ensuring better management baseline for decision-making. However, authors concluded that there are great differences in the practical applications of CI between these EU countries.

Literature review has shown that CI practices in Serbia have never been explored so far.

\section{RESEARCH METHODOLOGY, SAMPLEAND DATA COLLECTION}

The hypothesis tested is the current level of awareness and competitive intelligence implementation success in Serbian largest companies. We analyze influence of CI on business performance of companies operating in Serbia. We additionally ex- 
plored differences in CI awareness and implementation, by comparing summarized research data for Serbia companies and companies in other developed countries.

Hypothesis testing is based on summarizing and comparative analyzing of field data from a sample of 100 Serbian largest private companies by revenue, excluding banks and insurance companies. The sample pool consists of 100 companies listed in the 2013. Industry yearbook published by the Serbian Business Registry Agency. ${ }^{2}$ The reason for this is that previous CI surveys conducted in other countries implied that CI first spreads within biggest corporations, before it gets widely accepted in small and medium sized enterprises. Other reasons why we chose 100 Serbian largest companies are: large companies are more likely to disclose more information, and large companies are likely to possess more competitive intelligence experience because they are more visible and have more resources at their disposal to sponsor new initiatives.

Companies CEOs were the key informants in this study. Each informant received a letter with an explanation of the purpose of the study and a questionnaire by mail or email. These efforts elicited 22 completed questionnaires - useable responses, creating a final useable response rate of $22 \%$. Reasons for low response rate are: in several cases managers did not respond to the survey due to firm reorganization, some of managers involved did not consider appropriate to respond to the questionnaire. In other cases, the reason for not answering was a lack of time or interest in the research.

The questionnaire used in this study is based on two questionnaires used in other empirical CI surveys. Survey conducted by the SCIP (Society of Competitive Intelligence Professionals) targeting North American businesses, and survey done by Sugasawa investigating current state of CI activities and competitive awareness in Japanese Businesses 67 companies. With the exception of certain areas that have been deleted due to differences in industrial sectors between U.S. Japan and Serbia, for the purpose of this survey, nearly all the questions pertaining to competitive intelligence are the same.

For the purpose of this survey, the respondents were questioned about CI relevant information. Around 50 different answers were given to these questions. In order to guarantee a clear overview and to ease further analysis, similar responses were grouped into summarizing categories and in tables we highlight the summarized results.

The content analysis method involves codifying qualitative and quantitative information into pre-defined categories so that a pattern can be derived in presenting and reporting that information. This methodology allows the presentation of the information in a systematic, objective and reliable manner.

The presentation of the findings is structured in the same way as the research questions are. First, the structure of companies will be presented. Then, the data col-

2 Serbian Registry Agency - http://www.mc.rs/upload/documents/istrazivanje/2014/APR-STO-NAJprivrednih-drustava-Srbija-2013.pdf - accessed on June 4 th 2015. 
lection practices of Serbian CI workers will be highlighted and analyzed. Furthermore, several aspects of the CI process in Serbian companies will be illustrated. The last subsection of the findings will focus on perceived benefits of CI. All summarized research data for Serbia will be compared with available corresponding data and experiences of companies in other developed countries.

\section{RESEARCH RESULTS AND COMPARATIVE DATA}

Analyzed sample represents a well-proportioned mix of major Serbian companies from different industries. Table 1 . indicate that the largest percentage $(41 \%)$ of respondent companies were involved in production business - manufacturing of industrial and consumer products. The second most significant type of business organization represented was from the trade sector $(27 \%)$. These two sectors represented a significant percentage of the business types represented in the survey $(68 \%)$.

Table 1.: Type of Business or OrganizationS Represented

\begin{tabular}{|l|r|r|}
\hline \multicolumn{1}{|c|}{ Sector } & Number & \multicolumn{2}{c|}{ Percentage } \\
\hline Production & 9 & $41 \%$ \\
Communication & 2 & $9 \%$ \\
Finance & 2 & $9 \%$ \\
Trade & 6 & $27 \%$ \\
Others & 3 & $14 \%$ \\
Total $(\%$ of total) & 22 & $100 \%$ \\
\hline
\end{tabular}

Source: Research results.

\section{CI information sources}

There is a huge variety of competitors' information sources that can be used during the CI process. These sources can either be internal or external, personal or impersonal, formal or informal. Employees for example, especially those in direct contact with customers or clients, serve as a most valuable source of competitive intelligence. Competitors communicate extensively to their suppliers, customers, distributors, stockholders and government departments. Contact with any of these sources can provide information. Monitoring of trade magazines, trade shows, advertising, speeches, annual reports etc. can also be informative.

Careful selection of the data sources is very important. It is not really important which category of sources is used, the most important thing is that sources are trustworthy and reliable and that the information gathered is timely enough.

Respondents in this survey had to rank their three most important information sources Table 2. data show that internet, personal contacts and published in- 
formation are the most common source of information for CI in Serbia. Sources of CI information are quite similar in Belgium and South Africa (De Pelsmacker, at all, 2005), where company staff, personal contacts outside the company, and external distribution channels rank among the most important ones. The internet and existing as well as prospective employees are by far the most important information sources for CI purposes within Austrian companies. Empirically observed popularity of the internet and existing employees, as a CI primary information sources we also find in a study done for the UK (Wright, and Calof, 2006).

Table 2.: Source of information

\begin{tabular}{|l|r|r|}
\hline \multicolumn{1}{|c|}{ Items } & Percentage & \multicolumn{2}{c|}{ Rank } \\
\hline Internet & $55 \%$ & 1 \\
Personal contacts (network) & $45 \%$ & 2 \\
Published information & $45 \%$ & 2 \\
Prospective employees & $30 \%$ & 3 \\
Information from customers & $14 \%$ & 4 \\
and suppliers & $10 \%$ & 5 \\
Official authorities reports and & & \\
statistics & $5 \%$ & 6 \\
Press & & \\
\hline
\end{tabular}

Source: Research results,

The internet category summary in this study consists of information collection possibilities on publicly available websites such as competitors' websites as well as newsgroups, newsletters and online databases with viewing restrictions. As a competitive intelligence source, the Internet is both an additional source of information and a cost-effective means of sharing and disseminating information for decision makers. Company home pages often yield information about product lines, substitute products, complementary products and innovation. Companies also publicize press releases offering product information on their home pages (A.S.A., 2003: 115).

\section{Technical aids used for CI purposes}

Companies worldvide have great variety of tools and technologies on its disposal, that can be used for performing CI analyzes (Bouthillier, Jin, 2005: 43). Software providers offer special CI software, which improves competitor's data gathering process, simplify data mining and analysis procedures, and supports decision-making with a systematic CI information storage systems and databases. These software tools make entire CI process more efficient in providing useful and prompt information's for decision-makers.

However, the responses to the question whether the surveyed firms use technical aids (software) for reporting on competition (simplifying the CI process) yielded 
a clear result - no special CI software or other technical tools are currently used by Serbian companies ( Table 3.).

Table 3.: Do you have a special program / software for reporting on Competition

\begin{tabular}{|l|r|r|r|}
\hline $\begin{array}{l}\text { Software used for CI } \\
\text { purposes }\end{array}$ & yes & no & Total (\% of total) \\
Total nr. (\% of total) & $\circ(0 \%)$ & $19(100 \%)$ & $19(100 \%)$ \\
\hline
\end{tabular}

Source: Research results.

In Austria, beside few companies using databases for information storage and dissemination purposes, none reported using specialized software for CI purposes (Andreas, 2008: 44). Similar results were recorded for majority companies in EU countries (Michaeli R, 2004; Smith and Kossou, 2008; Wright, Badr, Weiss and Pickton, 2004; Tena and Comai, 2004; Stankeviciute at all, 2004).

Practical use of various software packages for gathering and dissemination of CI information was confirmed in the responses of Japanese companies (Sugasawa, 2004: 17), and in research for USA based companies done by Marin and Poulter (2004). These companies mentioned various software products, and confirmed that technological tools and software used by CI professionals have helped in information gathering and analyzing.

\section{Subject of CI analysis}

Positive aspect of modern age and electronic era is information availability. Majority of the needed information can be accessed easily, often without any costs involved. Companies must focus only on certain information when analyzing competitors and the environment. That is of critical importance for the overall performance and efficiency of a company, because managers are not able to use "all information at any time".

Listed below (Table 4.) are several categories of information which may be monitored for specific competitors. We asked respondents to indicate (1) how frequently they monitor each category of information, and (2) the extent of performed data analyzes, i.e. which competitor companies are monitored for each data category they are analyzing. For consistency, all responses in this question were measured using a Likert-type scale (1-5). For frequency of data collection: 5="Monthly," $4=$ "Quarterly", $3=$ "Semiannually", $2=$ "Annually," 1 ="Never". For extensiveness of analysis: 1 ="only market leader", 3 ="only current competitors," and 5="all competitors". 
Table 4.: Categories of Information Which May be Monitored for Specific Competitors

\begin{tabular}{|c|c|c|}
\hline Frequency of data collection & $\begin{array}{c}\text { Information Monitored } \\
\text { on Competitors }\end{array}$ & Extensiveness of analysis \\
\hline 3.8 & Technological developments & 3.75 \\
2.8 & Marketing & 4 \\
3.1 & General industry trends & 4 \\
2.6 & Customers & 4.4 \\
3.5 & Financial reports & 3.66 \\
4.1 & Products \& services & 4.5 \\
3.4 & Human resources & 3.5 \\
2.7 & Manufacturing operations & 3.75 \\
3 & Channels of distribution & 3.95 \\
3.8 & Prices \& conditions & 4.1 \\
1.1 & Organizational goals and & 2 \\
\hline
\end{tabular}

Source: Research results.

Almost all of the respondents named the products and services of the competitors as the most important research object. Companies in Serbia monitor products and services of all known market competitors, usually on monthly basis. In general, it is understandable that the competitors' products and services are the main focus for the majority of the researched companies because this is a company's most important property and this is where in most cases a unique selling proposition stems from. Furthermore, new trends can often be identified by the products of an industry and a company might directly derive the strengths and weaknesses of the competition as well as their own from the different product portfolios.

Collecting and analyzing data on the competitors' customers and prices and conditions, for all competitors, are also important objectives for most of the surveyed companies in Serbia. These data are usually monitored on a semiannual basis. Studies for Austria and Belgium reached similar conclusions. In Austria almost all of the respondents named the products and services of the competitors as an important research object. Another important objective for most of the surveyed companies was the collection of data on the competitors' prices and conditions (Andreas, 2008: 46). Another study finds that Belgium companies monitored following information: potential partners or agents, profiles of potential customers and opportunities in new markets. In SouthAfrica opportunities in new markets are on the first place following with potential partners or agents and trade fairs (De Pelsmacker at all, 2005: 614).

However, we find very interesting that Serbian and EU based companies don't consider information's regarding technological development of its competitors to be a primary focus, regardless of the fact that technological innovations can be the most important source of market competitive advantage. Opposite to above, in USA and 
Japan, two leading world economies, technological developments, marketing and sales and general industry trends are most frequently collected information (Marin and Poulter, 2004: 178; Sugasawa, 2004: 13-14).

\section{Dissemination of Competitive Intelligence}

Dissemination of CI outcomes is an important task for all CI practitioners because without this step, performed data analysis would be useless as the findings and intelligence would never be utilized. Looking at the ways of disseminating CI findings, and therefore summarizing the empirical as well as the theoretical findings (e.g. Marin and Poulter, 2004), it can be argued that overall, e-mails are the most popular means of CI distribution. The popularity of e-mails in this respect can be explained with the need for an immediate and fast communication of CI to numerous different recipients.

To investigate which methods of disseminating competitive intelligence findings Serbian companies usually practice, we point out these two questions: "Please indicate how extensively your unit uses each of the following methods of disseminating competitive intelligence. How effective is each method, in terms of providing useful information for decision-makers." All responses in this question were measured using a Likert-type scale (1-5). For extensiveness of use: 1 = "not used," 3="occasionally used," and $5=$ "extensively used,", and for effectiveness in providing usable information to decision-makers: 1 ="ineffective" 3 ="effective" and $5=$ "highly effective".

Table 5.: Methods of Disseminating Competitive Intelligence

\begin{tabular}{|c|c|c|}
\hline Extensiveness of use & $\begin{array}{c}\text { Methods of Disseminating } \\
\text { CI }\end{array}$ & $\begin{array}{c}\text { Effectiveness in providing } \\
\text { usable information to users }\end{array}$ \\
\hline 3.3 & Written or custom designed & 4.1 \\
3.6 & reports for end users & 3.8 \\
4.6 & Regular meetings & 4.6 \\
4.8 & Personal communications & 5 \\
3.3 & E-mail & 3.75 \\
2.3 & Intranet (computerized data & 2.5 \\
1.1 & bases) & 2 \\
\hline
\end{tabular}

Source: Research results.

Table 5., reveals that e-mails, personal communication and regular meetings are extensively used methods of CI disseminating in Serbian companies, which are at the same time considered as highly effective. In other words, it appears that there is core awareness of need for constant personal communicating CI using electronic and verbal methods. 
Hence, Serbian companies provided the same insights, in compare with existing literature and studies of methods of CI information's disseminating. Empirical study of USA, UK, Austria and China CI practices identifies newsletters and the intranet as most frequently used tools for communicating CI intelligence (Prescott, Bhardwaj, 1995; Wright, Badr, Weiss, and Pickton, 2004; Andreas, 2008; Tao, Prescott J. 2000), while in Japan, Germany and France those methods are "written or custom designed reports for end users", "presentation to end users", "computerized databases" and "regular meeting", whereas "presentations to end users" and "personal communications" are most effective way of communications. (Sugasawa, 2004; Michaeli , 2004; Smith and Kossou, 2008).

\section{CI information receivers within companies}

Data presented in Table 6., indicate that sales departments $(58 \%)$ are the primary users of competitive intelligence activities outputs, when it comes to Serbian business practices. The second largest users of CI information's support are marketing department.

Table 6.: Primary Users of the Outputs from Competitive Intelligence Activities

\begin{tabular}{|l|r|r|}
\hline \multicolumn{1}{|c|}{ Department } & Number & Percentage \\
\hline Marketing & 8 & $36 \%$ \\
R\&D & 1 & $4 \cdot 5 \%$ \\
Sales & 12 & $55 \%$ \\
Service & 0 & $0 \%$ \\
Finance/Accounting & 1 & $4 \cdot 5 \%$ \\
Manufacturing & 0 & $0 \%$ \\
Total (\% of total) & 22 & $100 \%$ \\
\hline
\end{tabular}

Source: Research results.

Presented results for Serbia companies are in line with the results reported for almost all EU countries. Majority of Belgian companies (62.9\%) and South African companies $(55.6 \%)$ reported that marketing and sales department is primary user of CI intelligence (De Pelsmacker at al, 2005). Similar results were reported for the USA based companies (Lackman et al (2000), and for companies operating in Austria (Andreas, 2008). Marin and Poulter (2004) study, further suggest that in terms of departments, the marketing department is the main user of CI.

On the contrary to Serbia and most EU companies, in Japan primary users of the CI outputs are "Manufacturing" (23\%) and "R\&D" (18\%) departments, (Sugasawa, $\mathrm{Y}, 2004:$ 12) testifying overall commitment to technology development and innovation of companies based in Japan. 
Table 7.: Hierarchy level of CI information receivers

\begin{tabular}{|l|r|r|}
\hline \multicolumn{1}{|c|}{ Items } & Number & \multicolumn{2}{|c|}{ Percentage } \\
\hline Upper management & 11 & $50 \%$ \\
Middle management & 4 & $18 \%$ \\
Equally by upper and middle & 7 & $32 \%$ \\
Other management levels & 0 & $\circ \%$ \\
Total (\% of total) & 22 & $100 \%$ \\
\hline
\end{tabular}

Source: Research results.

Table 7 . shows the results on management hierarchy levels that receives and use CI information's. Research revealed that the primary user of competitive intelligence activities in Serbia is "upper management" (50\%). However, respondents also reported very high rate $(32 \%)$ when information's provided by CI activities are used equally by both upper and middle managements level". This result confirms the value of CI for both strategic and tactical business decisions-making.

The Austrian respondents exclusively identified "upper management" (57\%), as the persons within their companies to whom they distribute their CI analyses. In Japan the outputs from competitive intelligence activities are used primarily by upper management $(57 \%)$, while on $(4,3 \%)$ respondents answer "Used equally by both". Presented results are also in line with the findings of the study carried out by Marin and Poulter, in which over 50 per cent of the respondents in USA identified top managers as the main users of CI.

\section{The extent of helpfulness of competitive intelligence}

It is proven that both tactical and strategic decision-making can and is supported by CI processes.

Study participants in Serbia were asked to explain and to highlight the benefits they gained from practicing CI within their companies. In order to investigate the extent of helpfulness of competitive intelligence we point out following question: "To what extent has competitive intelligence aided in achieving following company's goals?" The respondents were instructed to indicate and to define helpfulness of CI systems for different sets of company's objectives, with (1-5) scale: 1 = "doesn't help at all" to $5=$ "helped considerably). The responses to this question are presented by following Table 8. 
Table 8.: The Extent of Helpfulness of Competitive Intelligence

\begin{tabular}{|l|r|}
\hline \multicolumn{1}{|c|}{ Items } & Rank \\
\hline Identification of new business opportunities & \\
Improved market position & 4.4 \\
Improvement of managers' analytical capabilities & 4.1 \\
Increased revenues and/or profits & 4 \\
Sharing of ideas and knowledge in company & 3.6 \\
\hline
\end{tabular}

Source: Research results.

Research pointed that two most important benefits of competitive intelligence for companies based in Serbia are identification of new business opportunities and improving market position. These top two CI benefits were followed closely by improvement of managers' analytical capabilities. In Austria the most prominent reason for conducting CI, described as gaining better market knowledge regarding strengths and weaknesses of competitors and own market position, was put forward by more than 50\% of the respondents which used CI for benchmarking purposes (Andreas, 2008: 98). Furthermore, benefits stemming from CI activities that are often brought forward in respective literature (e.g. Britt, 2006) and were also mentioned by the most respondents are "decisions making assistance" and "risk reduction". In Japan identification of new business opportunities and sharing of ideas, are top two CI benefits, followed closely with reported benefits regarding improved market position of companies operating in this country.

Research results for Serbia, as well as comparative results of mentioned studies for other developed world countries, indicate that companies do not use CI primarily to increase revenues or profits. These findings confirm that CI systems main purpose is to provide base for strategic decision-making and for long-terms goals achieving.

\section{CONCLUSION}

As a relatively young discipline, competitive intelligence has not yet imposed itself in the Serbian exploration scientific community. This empirical research enriches literature regarding CI, and provides basis for future studies.

Survey results indicate that there are small differences in practical applications of CI between companies in Serbia and those in EU. Companies in Serbia had a later start with less of a sense of urgency of using CI approach, but are moving in the same general direction as the developed EU countries.

Companies operating in EU and Serbia reported high level of CI importance awareness, and confirmed various benefits and positive effects of CI activities on their business performance. Internet and employees are proven to be CI primary information sources for all EU and Serbia companies. Most of these companies already formed their CI databases, and are using many different types of data mining 
and analyzing procedures in order to create knowledge and informations that supports strategic decision-making and long-terms goals achieving. Their CI activities are mainly consumer-oriented. Competitors' products and services, customers, and prices and conditions are the three most important CI research objects. However, none special CI software or other technical tools are currently used for the purposes of CI outputs generating and disseminating to final users by EU and Serbian companies.

We indentified differences between the CI practices in Japan and USA on one side, and EU countries and Serbia on the other. Generally speaking, companies in Japan and USA use CI primarily for monitoring and supporting production innovations and development of new technologies. Serbian and EU based companies don't consider information's regarding technological development of its competitors to be a primary focus, regardless of the fact that technological innovations can be the most important source of market competitive advantage. Since Japan and USA companies are world leaders in innovations, it can be argued that companies in Serbia and EU should more often use CI outputs in order to improve their technologies and innovation capacities. Opposite to EU and Serbia, companies in USA and Japan confirmed substantial practical use of various CI software packages and tools for gathering, analyzing and dissemination of GI information.

Research conclusions imply that companies in Serbia and in EU must further explore benefits emerging from CI activities, especially by investing in specialized CI software packages, in order to improve their business performances, and gain necessary competitive advantage for the successful strategic positioning on EU market. 


\section{REFERENCES:}

Aguilar F.J., Scaning the Business Environment, (New York: NYMacMillan, 1967)

Andreas Roitner, "Competitive Intelligence in Austria: An empirical study", Universitad Wien, Mag. rer. soc. oec. Wien, at - http://othes.univie.ac.at/756/1/05-19-2008_ooo3246.pdf, (2008)

A.S.A. du Toit, International Journal of Information Management, vol. 23, (2003)

Britt, P., "The new competitive intelligence: Raising the confidence quotient", KMWorld, Vol. 15 (10), (2006)

Bouthillier F.I Jin T, "Competitive Intelligence Professionals and their Interactions with CI Technology: A Research Agenda", Journal of Competitive Intelligence and Management, Vol. (3) num 1., (2005)

Cobb Pamela, "Competitive Intelligence through Data Mining", Journal of Competitive intelligence and management, Vol. (1) num 3, (2003)

Daft R, "Chief executive scanning, environmental characteristics, and company performance: An empirical study", Strategic Management Journal, vol. (9), (1983)

De Pelsmacker, Marie-Luce Muller, Wilma Viviers and Andrea Saayman, Ludo Guyvers and Marc Jegers, "Competitive intelligence practices of South African and Belgian exporters", Marketing Intelligence \& Planning Vol. 23 No. (6), (2005)

Erickson, G.S., Rothberg, H.N., "Intellectual capital in business-to-business markets, Industrial Marketing Management", Vol. (38), Elsevier Inc., (2009)

Ganesh U., Miree C.E. I Prescott J., "Competitive intelligence field research: Moving the Field Forward by setting a research agenda", Journal of Competitive Intelligence and Management, vol 1. Num 1, 2003

Hannula, M., \& Pirttimaki, V., "Business intelligence empirical study on the top 50 Finnish companies", American Academy of Business, 2 (2), (2003)

Hedin, H., "Evolution of competitive intelligence in Sweden", Journal of Competitive Intelligence and Management, Vol. 2 (3), (2004)

Kersi D. Antia and James W. Hesford, "A Process-Oriented View of Competitive Intelligence and its Impact on Organizational Performance", Journal of Competitive Intelligence and Management, Volume (4), No. $1,(2007)$

Kumar K, Subramanian R, Strandholm K, "Competitive strategy", environmental scanning and performance : A context specific analysis of their relationship", IJCM, (11), (2001)

Lackman, C., Saban, K. and Lanasa, J. , "The contribution of marketing intelligence to tactical and strategic business decisions", Marketing Intelligence \& Planning, Vol. (18) No. 1, (2000)

Marin, J., \& Poulter, A. , "Dissemination of competitive intelligence", Journal of Information Science $3 \circ$ (2), (2004)

Michaeli, R., "Competitive intelligence in Germany", Journal of Competitive Intelligence and Management, Vol. 2 (4), (2004)

Porter M.E., "Competitive Strategy", (New York, NY Free Press, 1980)

Prescott, J. E. and Bhardwaj, G., "Competitive Intelligence Practices: A Survey", Competitive Intelligence Review, Vol. 6(2), (1995)

Smith \& Kossou, "The Emergence and Uniqueness of Competitive Intelligence in France", Journal of Competitive Intelligence and Management, Volume (4), No. 3, (2008) 
Stankeviciute, J., Oržekauskas, P. and Jucevicius, R., "Competitive Intelligence in Lithuania", Journal of Competitive Intelligence and Management, Vol.2 (4), (2004)

Stephanie Hughes, "Competitive Intelligence as Competitive Advantage: The Theoretical Link Between Competitive Intelligence, Strategy and Firm Performance" Journal of Competitive Intelligence and Management, Volume (3), Number 3, (2005)

Sugasawa, Y., "The Current State of Competitive Intelligence Activities and Competitive Awareness in Japanese Businesses", Journal of Competitive Intelligence and Management, , Vol. (2) (4), (2004)

Tao, Q. and Prescott, J., "China: Competitive Intelligence Practices in an Emerging Market Environment", Competitive Intelligence Review, Vol. (11) (4), (2000)

Tena, M. J. and Comai, A., "Competitive intelligence in Spain: a situational appraisal", Journal of Competitive Intelligence and Management, Vol. (2) (3), (2004)

Wright, S., Badr, A., Weiss, A. and Pickton, D. W., "Competitive intelligence through UK eyes", Journal of Competitive Intelligence and Management, Vol. (2) (2), (2004)

Wright, S. and Calof, J. L., "The quest for competitive, business and marketing intelligence", European Journal of Marketing, Vol. (4,0) (5/6), (2006) 
